\title{
A Comparative Study of Central Corneal Thickness and Intra Ocular Pressure in Diabetic and Non-Diabetic Patients in a Tertiary Care Hospital in Kumaon Region, Uttarakhand
}

\author{
Deepti Joshi ${ }^{1}$, Shanti Pandey², Vivekanand Satyawali ${ }^{3}$, Govind Singh Tityal ${ }^{4}$ \\ 1Department of Ophthalmology, Government Medical College, Haldwani, Uttarakhand, India. ${ }^{2}$ Department of \\ Ophthalmology, Government Medical College, Haldwani, Uttarakhand, India. ${ }^{3}$ Department of Ophthalmology, \\ Government Medical College, Haldwani, Uttarakhand, India. ${ }^{4}$ Department of Ophthalmology, Government Medical \\ College, Haldwani, Uttarakhand, India.
}

\section{ABSTRACT}

\section{BACKGROUND}

Diabetes mellitus is one of the most common metabolic diseases that has become an epidemic of $21^{\text {st }}$ century. Diabetes mellitus has a significant effect on morphology, physiology and clinical appearance of human cornea. Diabetic changes may manifest in the corneal epithelium basement membrane, stroma and endothelium. Glucose can act as a corneal cross-linking agent with the help of advanced glycation end product. The central corneal thickness is an important indicator of health of cornea. Higher central corneal thickness may affect the measurement of intraocular pressure (IOP), causing overestimation of the true intraocular pressure. Therefore, measurement of CCT and intraocular pressure has become an important ocular parameter in diabetics. We wanted to determine the correlation between central corneal thickness (CCT) and intraocular pressure changes in diabetic and non-diabetic patients.

\section{METHODS}

This is a cross sectional study conducted in the department of ophthalmology at a tertiary care centre of Kumaun region, among 400 subjects from age group of 40-80 years. Central corneal thickness was measured by pachymetry (optical coherence) and intraocular pressure determined by Goldmann applanation tonometer. The study included 400 subjects. Out of them, 200 were diabetic and 200 were non-diabetic patients.

\section{RESULTS}

In our study, the average central corneal thickness in diabetic patients was $526.29 \pm$ 24.69 microns and in non-diabetics the average central corneal thickness was 512.28 \pm 26.91 microns. Higher central corneal thickness found in diabetic patients compared to non-diabetic patients was statistically significant. $(\mathrm{p}<0.001)$. The mean IOP in diabetics was $15.99 \mathrm{mmHg}$ and in non-diabetics mean IOP was $14.51 \mathrm{mmHg}$. Intraocular pressure difference is also statistically significant $(\mathrm{p} \leq 0.001)$.

\section{CONCLUSIONS}

Diabetic patients have higher central corneal thickness, and thus, we get falsely high intraocular pressure when compared with the non-diabetic patients. Thus, higher CCT should be taken into account while measuring accurate intraocular pressure in diabetic individuals. Thus, higher CCT affects the measurement of intraocular pressure causing overestimation of intraocular pressure.

\section{KEY WORDS}

Intraocular Pressure, Central Corneal Thickness, Pachymetry, Diabetes Mellitus
Corresponding Author: Dr. Shanti Pandey, Associate Professor, Government Medical College Campus, Haldwani, Nainital-263139, Uttarakhand, India. E-mail: drshantipandey@gmail.com

\section{DOI: 10.14260/jemds/2019/804}

Financial or Other Competing Interests: None.

How to Cite This Article: Joshi D, Pandey S, Satyawali V, et al. A comparative study of central corneal thickness and intra ocular pressure in diabetic and non-diabetic patients in a tertiary care hospital in Kumaon region, Uttarakhand. J. Evolution Med. Dent. Sci. 2019;8(49):3715-3719, DOI: 10.14260/jemds/2019/804

Submission 09-10-2019, Peer Review 18-11-2019, Acceptance 25-11-2019, Published 09-12-2019. 


\section{BACKGROUND}

Type II diabetes mellitus is a major public health concern in this modern day. The prevalence of diabetes is very high in Indian subcontinent. Indian patients demonstrate certain distinct features i.e. onset at a younger age, obesity and genetic predisposition.1,2 Generally, there is delay of 4-7 years in the diagnosis of type 2 diabetes. About $20 \%$ patients had already developed micro vascular complications at the time of diagnosis. ${ }^{3}$

The thickness of cornea measures around 0.5-0.6 mm centrally and $1.2 \mathrm{~mm}$ at the periphery. ${ }^{4}$ The two different hypotheses behind higher CCT in diabetics are-

1. In the diabetic corneal endothelium, sorbitol accumulation within cells and a decrease in $\mathrm{Na}+\mathrm{K}+$ ATPase activity 5 induce dysfunction of the corneal endothelium cell layer leading to corneal hydration which translates to increased CCT measurements.

2. Stromal changes include structural alterations produced by collagen cross linking and advanced Maillard products accumulate in collagen proteins, result in the formation of covalent cross-linking bonds, and may lead to increased corneal thickening and biomechanical changes 6,7 that may cause increased stiffness of the cornea; this in turn may affect the measurement of intraocular pressure (IOP), causing overestimation of the true intraocular pressure.8,9

Intraocular pressure (IOP) is the fluid pressure inside the eye. Glaucoma is an optic neuropathy characterized by progressive degeneration of retinal ganglion cells (RGCs) and their axons, resulting in changes in the appearance of the optic disc and visual field loss. ${ }^{10}$ Although glaucoma is a multifactorial disease, elevated intraocular pressure (IOP) remains its major known risk factor. ${ }^{11}$ Diabetics are more prone to have primary open angle glaucoma. The risk of glaucoma has been reported to be 1.6-1.7 times higher in diabetics as compared to non-diabetics. ${ }^{12}$

Studies that hyperglycaemia can induce excess extracellular matrix synthesis by trabecular meshwork cells. This may cause extracellular matrix accumulation in trabecular meshwork, contributing to blockage of aqueous outflow. ${ }^{13}$ Goldman applanation tonometry is the gold standard for IOP measurement.

\section{METHODS}

Ethical clearance was obtained from the institutional ethical committee and a cross sectional study was designed in our tertiary eye care centre.

Sample size was estimated using the formula-

$\mathrm{n}=4 \mathrm{pq} / \mathrm{d}^{2}$

where $n=$ sample size, $\mathrm{p}=$ prevalence of diabetes in patients visiting OPD, q=100-p, $d=$ error in estimation.

Two hundred diabetic patients age between 40-80 years whether on treatment or not, who gave consent were enrolled irrespective of level of blood sugar. Two hundred age matched controls (non- diabetic by history and blood sugar level) were also enrolled. Complete ophthalmological and systemic examination was done. Fasting blood sugar post prandial blood sugar estimated on fully automated analyser (ROCHE) Cobas 501c based on the principle of hexokinase method, $\mathrm{HbA} 1 \mathrm{c}$ determination was done on the basis of turbidimetric inhibition immunoassay (TINIA), in all the cases. The central corneal thickness was done in all the diabetic and non-diabetic subjects with the help of optical coherence pachymeter and intraocular pressure measurement done by Goldmann applanation tonometer.

\section{Study Period}

October 2016 to October 2018.

\section{Exclusion Criteria}

1. All cases who had corneal pathology which can alter the thickness of cornea.

2. Diagnosed cases of glaucoma.

3. Patients using contact lenses for long time and had undergone any intraocular surgery.

4. Patients who did not given consent for participation in study.

\section{Statistical Analysis}

The collected data were transformed into variables, coded and entered in Microsoft Excel. Data were analysed and statistically evaluated using SPSS-PC-17 version. Quantitative data was expressed in mean, standard deviation and difference between two comparable groups were tested by student ' $\mathrm{t}$ ' test or Mann Whitney ' $\mathrm{U}$ ' test while qualitative data were expressed in percentage. Quantitative data between more than 2 groups were compared by ANNOVA test or Kruskal Wallis $\mathrm{H}$ test. The difference between the proportions was tested by chi square test. 'P' value less than 0.05 was considered statistically significant.

\section{RESULTS}

There were 400 patients included in this study with age group of 40 to 80 year. Majority of the patients belongs to age group 51-60 years (33.75\%) and 71 -80 years age group were found to be least common (9\%). Mean Age of diabetic, non-diabetics patients was $58.23 \pm 9.77$ years and $56.59 \pm 9.85$ years respectively (Table 1). This study shows that in non-diabetic group 99 (49.5\%) were males and 101 (50.5\%) were females with a M: F ratio of 0.98 . However, in diabetic group, 96 $(48.0 \%)$ cases were males and $104(52.0 \%)$ were females with a $\mathrm{M}$ : F ratio of 0.91 . Diabetic females have slightly higher preponderance $52.2 \%$. (Table 1 ) In this study, in diabetic group mean CCT was $526.29 \mu \mathrm{m}$ and in non-diabetics CCT were $512.28 \mu \mathrm{m}$. Mean CCT was significantly high in diabetic group as compared to non-diabetic patients i.e. p value $<0.001$.

CCT tends to increase significantly with duration of diabetes with $\mathrm{p}$ value $(<0.001)$. The highest CCT in right and left eye of diabetic were $588 \mu \mathrm{m}$ and $586 \mu \mathrm{m}$ respectively. (Table 2 and figure 1)

- The highest CCT in right and left eye of non-diabetic were $606 \mu \mathrm{m}$ and $604 \mu \mathrm{m}$ respectively.

- $\quad$ The lowest CCT in right and left eye of diabetic were 441 $\mu \mathrm{m}$ and $444 \mu \mathrm{m}$ respectively. 
- The lowest CCT in right and left eye of non- diabetic were $434 \mu \mathrm{m}$ and $437 \mu \mathrm{m}$ respectively.

Table 3 and figure 2 show that mean IOP in diabetics were $15.49 \mathrm{mmHg}$ and in non-diabetics mean IOP were 14.51 mmHg. Mean IOP was significantly high in diabetics as compared to non- diabetics (i.e. p value $<0.001$ ).

- Standard deviation was higher in diabetics that is 3.44 $\mathrm{mmHg}$, in non-diabetics it was $3.19 \mathrm{mmHg}$.

- $\quad$ The highest IOP recorded in diabetic group were 24 and $23 \mathrm{mmHg}$ in right and left eye respectively.

- $\quad$ The highest IOP recorded in non-diabetic group were 23 $\mathrm{mmHg}$ and $22 \mathrm{mmHg}$ respectively in right and left eye respectively.

- Lower limit of intraocular pressure in both the groups were $9 \mathrm{mmHg}$.

\begin{tabular}{|c|c|c|c|c|c|c|}
\hline Age & \multicolumn{2}{|c|}{ Diabetic } & \multicolumn{2}{c|}{ Non-Diabetic } & \multicolumn{2}{c|}{ Total } \\
\hline & No & $\mathbf{\%}$ & No & \% & No. & \% \\
\hline 40 - 50 years & 49 & 24.5 & 66 & 33.0 & 115 & 27.75 \\
\hline 51-60 years & 68 & 34.0 & 67 & 33.5 & 135 & 33.75 \\
\hline $61-70$ years & 63 & 31.5 & 51 & 25.5 & 114 & 28.5 \\
\hline $71-80$ years & 20 & 10.0 & 16 & 8.0 & 36 & 9.0 \\
\hline Total & 200 & 50.0 & 200 & 50.0 & 400 & 100 \\
\hline Male & 96 & 48.0 & 99 & 49.5 & 195 & 48.8 \\
\hline Female & 104 & 52.0 & 101 & 50.5 & 205 & 51.2 \\
\hline Total & $\mathbf{2 0 0}$ & $\mathbf{1 0 0}$ & $\mathbf{2 0 0}$ & $\mathbf{1 0 0}$ & $\mathbf{4 0 0}$ & $\mathbf{1 0 0}$ \\
\hline
\end{tabular}

Table 1. Distribution of Patients According to Age and Gender $(n=400)$

\begin{tabular}{|c|c|c|c|c|c|}
\hline \multirow{2}{*}{ Central Corneal Thickness $(\mu \mathrm{m})$} & \multicolumn{2}{|c|}{ Diabetic } & \multicolumn{2}{|c|}{ Non-Diabetic } & \multirow[b]{2}{*}{$\mathbf{p}$} \\
\hline & Mean & SD & Mean & SD & \\
\hline Right eye & 526.30 & 24.72 & 512.32 & 26.94 & $<0.001$ \\
\hline Left eye & 526.28 & 24.66 & 512.24 & 26.88 & $<0.001$ \\
\hline All eye $(n=800)$ & 526.29 & 24.69 & 512.28 & 26.91 & $<0.001$ \\
\hline
\end{tabular}

\begin{tabular}{|c|c|c|c|c|c|}
\hline \multirow{2}{*}{ Intraocular Pressure (mmHg) } & \multicolumn{2}{|c|}{ Diabetic } & \multicolumn{2}{|c|}{ Non- Diabetic } & \multirow[b]{2}{*}{$\mathbf{p}$} \\
\hline & Mean & SD & Mean & SD & \\
\hline Right eye & 15.81 & 3.36 & 14.35 & 3.25 & $<0.001$ \\
\hline Left eye & 15.17 & 3.32 & 14.66 & 3.13 & $<0.001$ \\
\hline All eye $(n=800)$ & 15.49 & 3.34 & 14.51 & 3.19 & $<0.001$ \\
\hline \multicolumn{6}{|c|}{$\begin{array}{c}\text { Table 3. Mean of Intra Ocular Pressure in } \mathrm{mmHg} \text { in } \\
\text { Diabetic and Non-Diabetic Patients }(n=400)\end{array}$} \\
\hline
\end{tabular}

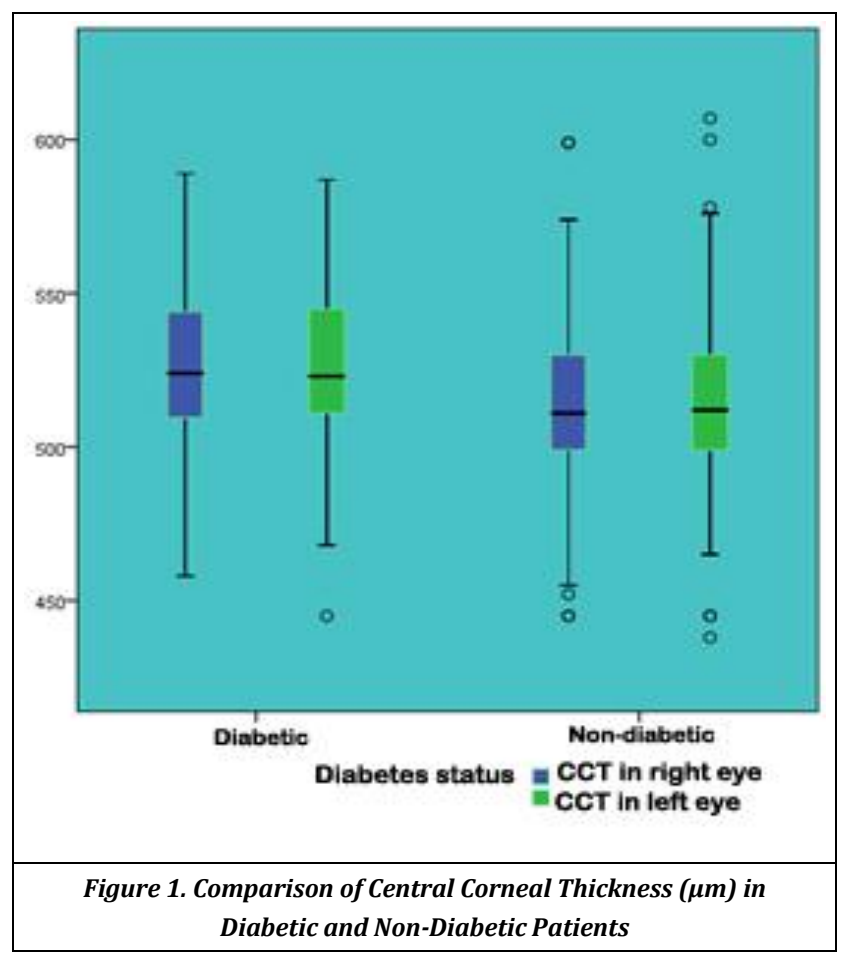

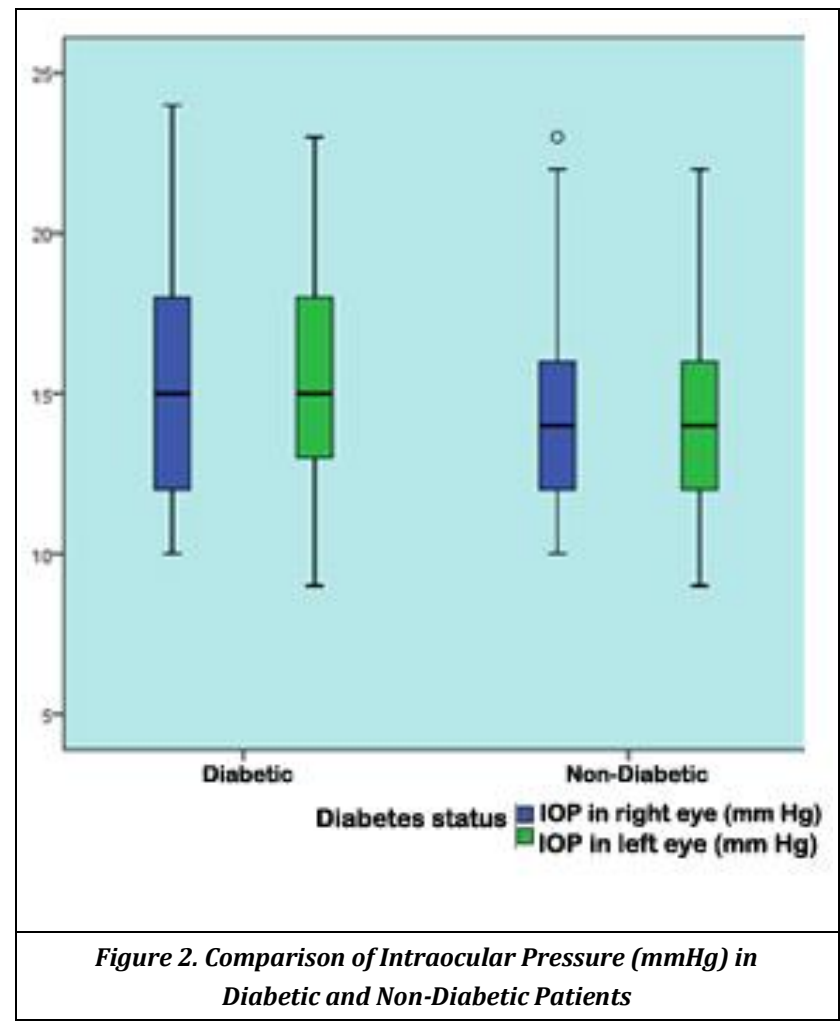

\section{DISCUSSION}

There has been considerable interest in the impact of some corneal parameters, especially CCT, as a potential determinant of measured IOP and glaucoma risk and/or progression.

In present study the average central corneal thickness in diabetic patients was $526.29 \pm 24.69$ micro meter and the average central corneal thickness found in non-diabetic patients was $512.28 \pm 26.91$ microns, which is similar from another study done on Indian eyes by Nangia et al with average central corneal thickness $(514 \pm 33.0 \mu){ }^{14}$ Rashmi Kumari et al ${ }^{15}$ Prempal Kaur et al ${ }^{16}$ concluded that the Diabetic patients had thicker cornea as compared to the non-diabetics.

Su et al. ${ }^{17}$ also observed that among 3280 Malay adults aged 40 to 80 years, those with diabetes and hyperglycaemia showed significantly thicker central corneas, which were independent of age and IOP levels Abdulghani et $\mathrm{al}^{18}$ in Sudanese population reported similar results as present study.

In contrast Kenji Inoue et $\mathrm{al}^{19}$ in Japan, compare the endothelial structure and thickness of the cornea in diabetic and non-diabetic patients. They found no significant difference between CCT in the diabetic group to non -diabetic individuals. Corneal endothelial cell structure was damaged, but CCT was not increased in type II diabetic patients.

This study shows that mean IOP in diabetics were 15.99 $\mathrm{mmHg}$ and in non- diabetics mean IOP were $14.51 \mathrm{mmHg}$. Mean IOP was significantly higher in diabetics as compared to non- diabetics. The reason behind higher IOP in diabetics is that that hyperglycaemia can induce excess extracellular matrix synthesis by trabecular meshwork cells. This may cause extracellular matrix accumulation in trabecular meshwork, contributing to blockage of aqueous outflow. ${ }^{14}$ In a study by Sato $\mathrm{T}$ et $\mathrm{al}^{20} \mathrm{using}$ an in vitro cell culture model, they have shown that trabecular meshwork cells grown in high- 
glucose condition up regulates mRNA and protein synthesis of fibronectin, an extracellular matrix component.

Stella Briggs et $\mathrm{al}^{21}$ evaluated central corneal thickness (CCT), corneal endothelial cell density (ECD) and intraocular pressure (IOP) in 125 patients compared with 90 age-matched controls in a prospective, randomized study at $\mathrm{Al}$ Hokama Eye Specialist Center, Riyadh, Saudi Arabia in 2013. In the diabetic group, the mean ECD), mean CCT and mean IOP) varied significantly from those the control group. Maggie B. Hymowitz et al suggested similar result as above study. Sahin A1, Bayer A et $\mathrm{al}^{22}$ conducted study on corneal biomechanical changes in diabetic individual of Turkish citizens (Caucasian origin) concluded that corneal hysteresis (corneal viscoelasticity) is significantly lower in diabetics when compared with healthy control subjects Mean CCT, GAT IOP were significantly higher in diabetic patients than in healthy control subjects.

Shikha Baisakhiya et al. ${ }^{23}$ Oshitari T et al. ${ }^{24}$ investigated the effect of chronic hyperglycaemia on intraocular pressure (IOP)in patients with diabetes and they report chronic hyperglycaemia is meaningfully associated with increased IOP in patients with diabetes.

\section{CONCLUSIONS}

Diabetic patients have higher central corneal thickness and hence we get falsely high intraocular pressure when compared with the non-diabetic patients. Therefore, the measurement of central corneal thickness and intraocular pressure is of paramount importance in diabetics in ophthalmic clinics. Although diabetic retinopathy leads to severe vision loss, keratopathy should also be recognized as a major complication in diabetic patients, as the diabetic cornea has higher potential to decompensate following stress. Higher central corneal thickness may affect the measurement of intraocular pressure (IOP), causing overestimation of the true intraocular pressure. Therefore, measurement of CCT and intraocular pressure should be taken into consideration in diabetics.

\section{ACKNOWLEDGEMENT}

The authors acknowledge Dr. Govind Singh Tityal, Prof. \& Head, Department of Ophthalmology.

\section{REFERENCES}

[1] Joshi R. Metabolic syndrome - emerging clusters of the Indian phenotype. J Assoc Physicians India 2003;51:4456.

[2] Deepa R, Sandeep S, Mohan V. Abdominal obesity, visceral fat and type 2 diabetes. Asian Indian phenotype. In: Mohan V, Rao GHR, eds. Type 2 Diabetes in South Asians: epidemiology, risk factors and prevention. New Delhi: Jaypee Brothers Medical Publishers (P) Ltd., 2006: p. 13852.

[3] Harris MJ, Klein R, Welborn TA, et al. Onset of NIDDM occurs at least 4-7 years of clinical diagnosis. Diabetes Care 1992;15(7):815-9.
[4] Rufer F, Schroder A, Erb C. White-to-white corneal diameter: normal values in healthy humans obtained with the Orbscan II topography system. Cornea 2005;24(3):259-61.

[5] O'Donnell C, Efron N, Boulton AJ. A prospective study of contact lens wear in diabetes mellitus. Ophthalmic Physiol Opt 2001;21(2):127-38.

[6] Ziadi M, Moiroux P, D'Athis P, et al. Assessment of induced corneal hypoxia in diabetic patients. Cornea 2002;21(5):453-7.

[7] Kara N, Yildirim Y, Univar T, et al. Corneal biomechanical properties in children with diabetes mellitus. Eur J Ophthalmol 2013;23(1):27-32.

[8] Sady C, Khosrof S, Nagaraj R. Advanced Maillard reaction and crosslinking of corneal collagen in diabetes. Biochem Biophys Res Commun 1995;214(3):793-7.

[9] Goldich Y, Barkana Y, Gerber Y, et al. Effect of diabetes mellitus on biomechanical parameters of the cornea. J Cataract Refract Surg 2009;35(4):715-9.

[10] Weinreb RN, Khaw PT. Primary open-angle glaucoma. The Lancet 2004;363(9422):1711-20.

[11] Kass MA, Heuer DK, Higginbotham EJ, et al. The Ocular Hypertension Treatment Study: a randomized trial determines that topical ocular hypotensive medication delays or prevents the onset of primary open-angle glaucoma. Archives of Ophthalmology 2002;120(6):701-13.

[12] Reynolds DC. Relative risk factors in chronic open-angle glaucoma: an epidemiological study. Am J Optom Physiol Opt 1977;54(2):116-20.

[13] Li A, Chen A, Roy S. High glucose-induced fibronectin overexpression inhibits trabecular meshwork cell permeability. Investigative Ophthalmology \& Visual Science 2003;44:1151. (ARVO): E-Abstract.

[14] Nangia V, Jonas JB, Sinha A, et al. Central corneal thickness and its association with ocular and general parameters in Indians: the central India Eye and Medical Study. Ophthalmology 2010;117(4):705-10.

[15] Kumari R, Saha BC. Central corneal thickness and diabetes-a study of correlation in terms of duration and glycemic control. Int $\mathrm{J}$ of Contemp Med Res 2017;4(3):767-9.

[16] Kaur P, Singh B, Bal BS, et al. Central corneal thickness in type 2 diabetic patients and its correlation with duration, Hba1c levels and severity of retinopathy. Group (NPDR). IOSR J of Dent and Med Sci (IOSR-JDMS) 2016;15(6):91-4.

[17] Su DH, Wong TY, Wong WL, et al. Diabetes, hyperglycemia and central corneal thickness: the Singapore Malay Eye Study. Ophthalmology 2008;115(6):964-8.e1.

[18] Abdulghani YS, Ali TO. Correlation between central corneal thickness and diabetes in Sudanese patients. Natl J Med Res 2013;3(4):309-11.

[19] Inoue K, Kato S, Inoue Y, et al. The corneal endothelium and thickness in type II diabetes mellitus. Japanese Journal of Ophthalmology 2002;46(1):65-9.

[20] Sato T, Roy S. Effect of high glucose on fibronectin expression and cell proliferation in trabecular meshwork cells. Investigative Ophthalmology \& Visual Science 2002;43(1):170-5. 
[21] Briggs S, Osuagwu UL, AlHarthi EM. Manifestations of type 2 diabetes in corneal endothelial cell density, corneal thickness and intraocular pressure. Journal of Biomedical Research 2016;30(1):46-51.

[22] Sahin A, Bayer A, Ozge G, et al. Corneal biomechanical changes in diabetes mellitus and their influence on intraocular pressure measurements. Investigative Ophthalmology \& Visual Science 2009;50(10):4597-604.
[23] Baisakhiya S, Garg P, Singh S. Association between glycemic control and intraocular pressure in patients with Type II diabetes mellitus. National Journal of Physiology, Pharmacy and Pharmacology 2017;7(1):43-6.

[24] Oshitari T, Fujimoto N, Hanawa K, et al. Effect of chronic hyperglycemia on intraocular pressure in patients with diabetes. American Journal of Ophthalmology 2007;143(2):363-5. 